\title{
Kajian Kebijakan Pengenaan Cukai Minuman Berpemanis
}

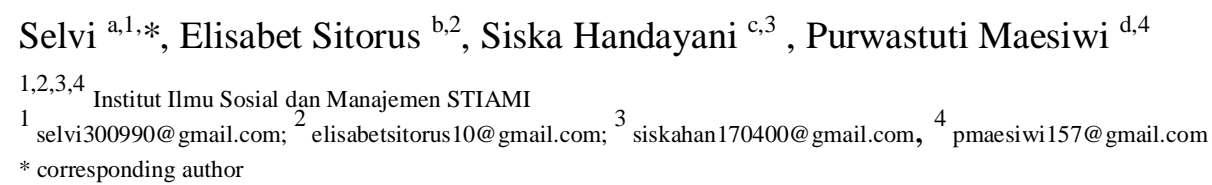

\section{ARTICLE INFO}

\section{Article history}

Received 2020-02-02

Revised 2020-05-05

Accepted 2020-06-22

Keywords

Excise

Sugary drink

Diabetics

Economy

\begin{abstract}
The increase in diabetics due to sugary drinks needs to be controlled. The imposition of excise on sweetened drinks has been implemented in several countries. This study aims to examine the aspects of tax collection for sweetened drinks in Indonesia and their impact. The research method is qualitative research. The results showed that the imposition of excise on sweetened drinks could give impact on reducing consumption of sweetened drinks but give a negative impact on the economy.
\end{abstract}

\section{PENDAHULUAN}

Diabetes merupakan salah satu penyakit yang menyebabkan kematian secara bertahap. kelainan sekresi insulin atau kerja insulin (Manurung \& Panjaitan:2019). Sebagai mother of disease atau ibu dari penyakit-penyakit lain diabetes dapat menimbulkan adanya penyakit-penyakit baru, seperti hipertensi, penyakit jantung dan pembulu darah, stroke, gagal ginajal, dan kebutaan (Pedoman Pengendalian Diabetes Melitus dan Penyakit Metabolik: 2008). Penderita diabetes jika memiliki luka akan sulit bahkan memerlukan waktu yang lama untuk sembuh dan dapat menimbulkan pembusukan/gangren sehingga, anggota tubuh yang mengalami pembusukan dapat berakhir pada proses amputasi. Banyaknya penderita Diabetes Melitus membuat negara Indonesia menduduki posisi ke-4 dengan jumlah 8,4 juta penduduk penderita diabetes pada tahun 2000 dan diperkirakan akan meningkat pada tahun 2030 dengan penderita sebanyak 21,3 juta penduduk Indonesia (InfoDATIn :2018).

Masalah perihal penyakit diabetes yang berujung pada komplikasi membuat pemerintah harus mengeluarkan biaya kesehatan yang besar melalui BPJS. Menurut Dr.Dwi Martiningsih sebagai Deputi Direksi Bidang Jaminan Pembiayaan kesehatan Primer BPJS Kesehatan, Diabetes sebagai penyakit kronis mengeluarkan biaya yang besar pada BPJS, yakni mencapai Rp. 6,1 Triliun (Beritagar 02/07/19), dimana $87,5 \%$ digunakan untuk pasien diabetes yang sudah memasuki tahap komplikasi. Oleh sebab itu, maka diperlukan suatu kebijakan guna menekan jumlah penderita diabetes di Indonesia.

Salah satu penyebab diabetes ialah konsumsi minuman berpemanis dan berkarbonasi secara berlebihan. Sesuai dengan namanya, minuman berpemanis dan berkarbonasi mengandung gula dan/atau pemanis buatan, contohnya teh kemasan, minuman bersoda, punch buah, minuman berenergi, kopi kemasan, dan lain sebagainya. Adapun satu kaleng kemasan minuman berpemanis mengandung tujuh hingga sepuluh sendok teh gula sebesar 4,2 gram (CNN Indonesia20/02/2020). Bahkan Minuman berpemanis di Indonesia dapat mengandung 37-54 gram gula dalam kemasan saji 300-500 ml. Jumlah ini melebihi 4 kali rekomendasi penambahan gula yang aman pada minuman, yaitu 6-12 gram dan menyumbang 310-420 kkal (Akhriani et al:2016).

Tingginya Prevelensi penderita diabetes di Indonesia memberikan eksternalitas negatif terhadap produk yang dikonsumsi, dalam hal ini adalah berbagai jenis minuman berpemanis. Pada tahun 2014, jumlah konsumsi atas minuman berpemanis di Indonesia mencapai 780 juta liter (Rosyada and Ardiansyah: 2018). Teh menjadi salah satu minuman berpemanis yang paling digemari masyarakat Indonesia, dengan presentase konsumsi sebesar 23\% (Nielsen: 2018). Begitupun dengan minuman berkarbonasi yang di anggap dapat memuaskan rasa haus lebih baik dibanding jenis cairan lain (Vice 16/01/2018). Berikut adalah data trend pertumbuhan minuman ringan berpemanis di Indonesia 


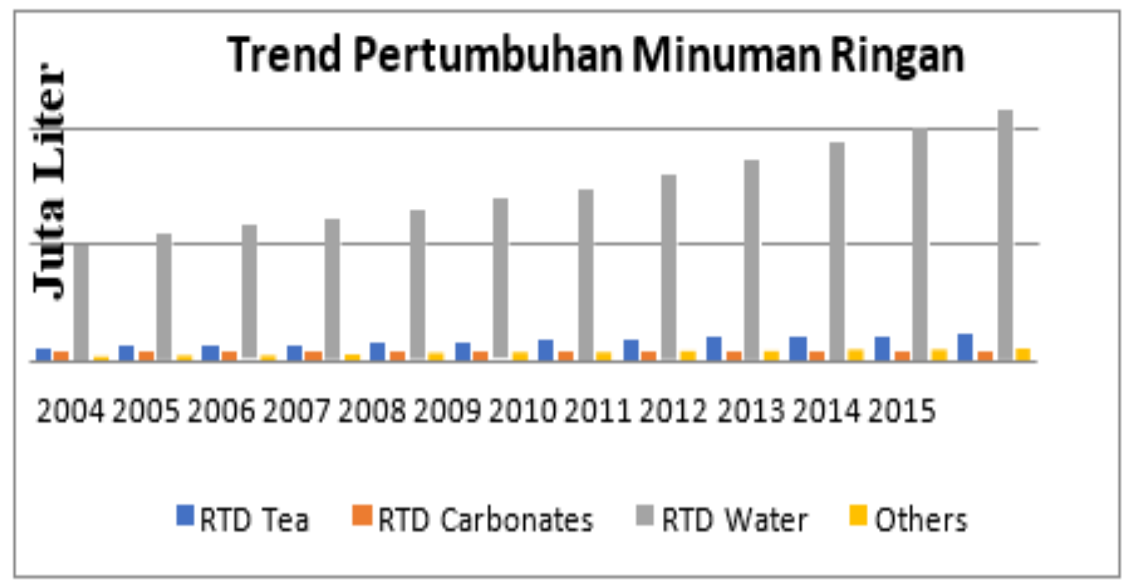

Gambar 1. Trend Pertumbuhan Minuman Ringan

Sumber: Euromonitor diolah oleh ASRIM.

Penyakit diabetes memiliki presentase tinggi di daerah perkotaan .DKI Jakarta merupakan kota dengan presentase tertinggi mengenai Prevalensi Diabetes Melitus pada penduduk di semua umur di tahun 2018 (RISKESDAS: 2018). Hal ini disebabkan pengaruh dari pendapatan pribadi terhadap konsumsi dimana, pengukuran keterjangkauan produk merupakan ukuran yang sangat diperlukan untuk memahami dan memprediksi keputusan konsumen dalam pembelian minimum yang dimaniskan dengan gula. Blecher, et al (2017) menyimpulkan bahwa minuman berpemanis dengan harga yang semakin terjangkau akan mendorong peningkatan konsumsi produk tersebut dan akan menghambat upaya global untuk mengatasi pandemi kelebihan berat badan dan obesitas. Adapun penelitian ini menggunakan sampel coca-cola sebagai salah satu minuman berpemanis di dunia dengan mengidentifikasi peningkatan keterjangkauan minimum.

Prevalensi Diabetes Melitus di Indonesia berdasarkan Diagnosis Dokter 2018 berdasarkan usia, jenis kelamin, dan tempat tinggal

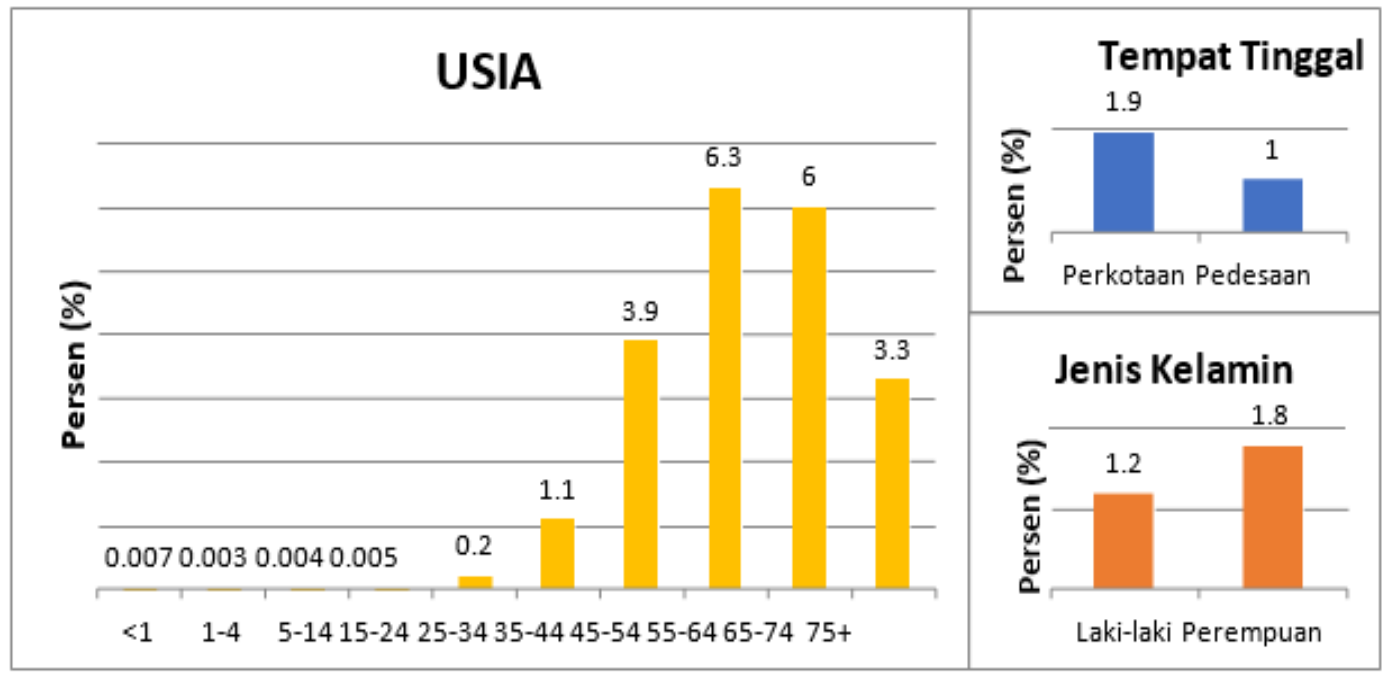

Gambar 2. Berdasarkan usia, jenis kelamin, dan tempat tinggal

Sumber: RISKESDAS (2018)

Oleh karena minuman berpemanis dan berkarbonasi memberikan dampak yang negatif bagi kesehatan masyarakat yang berujung pada kerugian secara finansial, dirasa perlu untuk diterapkan pungutan tambahan atas minuman tersebut. Dengan adanya pungutan tambahan itu, maka harga minuman berpemanis dan berkarbonasi akan lebih tinggi sehingga diharapkan mampu menekan konsumsi masyarakat. Prinsip ekonomi klasik mengatakan bahwa semakin harga naik maka permintaan akan turun. 
Sebagai contoh di Berkeley, California dimana pungutan atas minuman berpemanis mampu menurunkan konsumsi minuman berpemanis sebesar 21\% (Roache \& Gostin: 2017).

Namun perlu juga dipertimbangkan dampak pengenaan pungutan tersebut secara makro misalnya keberlangsungan usaha minuman berpemanis dan berkarbonasi. Dengan penurunan permintaan atas minuman tersebut secara otomatis akan berdampak pada penurunan pendapatan usaha yang berujung pada pemutusan hubungan kerja. Sebagai contoh pungutan atas minuman berpemanis di Arab Saudi justru berujung pada pengurangan karyawan (Alsukait, et al:2020), Selain itu, secara fiscal khususnya pendapatan pajak juga berpotensi turun akibat turunnya Pajak Penghasilan Badan yang berasal dari usaha minuman tersebut, Pajak Penghasilan Orang Pribadi yang bekerja pada perusahaan minuman serta Pajak Pertambahan Nilai atas penjualan minuman berpemanis berpemanis.

Dalam penelitian ini, peneliti akan mengkaji pungutan atas minuman berpemanis dan bersoda di Indonesia. Hal ini terkait dengan wacana pemerintah untuk mengenakan cukai atas minuman berpemanis sebagaimana tercantum dalam Rencana Pembangunan Jangka Menengah Nasional (RPJMN) 2020-2024. Meskipun beberapa penelitian telah mengkaji pungutan ini, namun penelitian ini berbeda dengan penelitian sebelumnya dimana dalam penelitian ini akan dikaji aspek pemungutannya baik dari sisi tarif, sistem pemungutan, objek, subjek hingga pengalokasian dana yang diterima dari pemungutan ini. Selain itu, peneliti juga akan mengkaji dampak yang akan ditimbulkan atas pungutan minuman berpemanis dan berkarbonasi dengan memperhatikan kondisi sosial dan ekonomi masyarkat Indonesia pada umumnya.

\section{METODE}

Penelitian ini menggunakan pendekatan kualitatif. Data primer didapatkan dari hasil wawancara dengan beberapa produsen, penjual serta konsumen minuman berpemanis. Selain itu, data primer juga didapatkan melalui observasi perilaku konsumen minuman berpemanis. Studi literatur juga dilakukan guna mendapatkan data sekunder yang akan digunakan untuk membandingkan hasil yang diperoleh data primer dengan penelitian terdahulu. Setelah data primer maupun sekunder didapatkan kemudian data tersebut diolah dan kemudian direduksi guna menjawab research questions

\section{HASIL DAN PEMBAHASAN}

\section{Aspek Pungutan Minuman Berpemanis dan Berkarbonasi}

\section{Jenis Pungutan : Pajak VS Cukai}

Secara umum, pajak dan cukai sama-sama merupakan pungutan yang dilakukan negara. Pajak, berdasarkan defisinisinya, merupakan iuran atau pungutan wajib dan bersifat memaksa kepada negara dengan tidak memperoleh kontraprestasi secara langsung yang digunakan untuk membiayai keperluan pemerintah. Dari definisi ini dapat disimpulkan bahwasanya pajak ialah pungutan negara yang bersifat umum dan secara fungsinya lebih mengarah kepada fungsi budgetair. Sedangkan cukai ialah pungutan negara terhadap barang-barang yang memiliki karakteristik tertentu. Karakteristik tertentu ini pada umumnya terletak pada eksternalitas negatif yang ditimbulkan. Fungsi cukai sendiri sebenarnya lebih mengarah pada fungsi regurelend yakni mengatur yang lebih spesifiknya ialah untuk membatasi konsumsi masyarakat akan barang tertentu. Pungutan atas minuman berpemanis dan berkarbonasi bertujuan untuk membatasi konsumsi masyarakat. Oleh karena itu, lebih tepat atas pungutan atas minuman berpemanis dan berkarbonasi ini berupa cukai.

Selain dari sudut pandang terminologi, pemungutan cukai berfokus pada barang tertentu sehingga pengawasan akan lebih spesifik dan efektif dibanding pajak. Pengawasan pemungutan cukai bisa dikatakan lebih ketat dibandingkan pengawasan pemungutan pajak karena dalam pemungutan cukai terdapat pengawasan fisik yang dilakukan oleh Bea Cukai alias official assessment. Hal ini karena official assessment system merupakan sistem pemungutan dimana perhitungan dan penentuan tarifnya dilakukan oleh fiscus atau pemerintah (Tansuria: 2012). Meskipun demikian, tidak dapat dipungkiri bahwa dengan pemberian wewenang penuh kepada fiskus dapat memperbesar resiko terjadinya KKN (Korupsi, Kolusi dan Nepotisme). Kejadian tersebut dapat di sebabkan salah satunya karena ketidakjujuran fiskus dengan menyalahgunakan kewenangannya, dimana pemasukan cukai yang seharusnya masuk ke kas negara justru digunakan untuk memperkaya diri sendiri (Tansuria: 2012), sedangkan pemungutan pajak lebih banyak 
merujuk pada self-assessment dan withholding system yang mengandalkan kepatuhan Wajib Pajak.

Terdapat beberapa negara yang menerapkan pemungutan berupa pajak maupun cukai, diantaranya UK dengan SDIL (Soft Drinks Industry Levy) yang menggunakan pemungutan berupa pajak pada tahun 2018 (Buckton, et al: 2019). Pungutan berupa pajak ini juga dilakukan di Meksiko sejak 2013 dengan Sugar-sweetened Beverages Tax, yang diikuti juga oleh 23 negara dan delapan yurisdiksi di Amerika Serikat (James, et al: 2020), sedangkan negara dengan pemungutan berupa cukai adalah Arab Saudi, Uni Emirat Arab serta Bahrain pada tahun 2017 dan kemudian diikuti oleh Qatar dan Oman pada 2019 (Alsukait, et al: 2020), selain itu Meksiko, Perancis, Denmark dan Barkeley juga menggunakan pemungutan berupa cukai (Falbe, et al: 2015).

\section{Subjek Pungutan}

Perihal siapa pihak yang dipungut, subjek pungutan minuman berpemanis dan berkarbonasi ialah produsen produk tersebut apabila produk diproduksi di dalam negeri. Sedangkan apabila produk bukan merupakan barang yang diproduksi di dalam negeri alias impor, maka pungutan dikenakan terhadap importer. Subjek dari cukai minuman berpemanis merupakan Pabrik dan importir yang sifat pengenaan tarif cukainya secara spesifik multi tarif atau berdasarkan kandungan gula pemanis buatan.. Berikut adalah data perbandingan jumlah produsen dalam negeri vs importir minuman berpemanis:.

No Jumlah Industri minuman kemasan di indonesia (Terdaftar Sebagai Anggota ASRIM)

1. PT. Coca-cola Indonesai

2. PT. Sinar Sosro

3. PT. Nestle Indonesai

4. PT Tirta Investama

5. $\quad$ PT. Unilever Indonesai

6. PT. Amerta Indah Otsuka

7. PT. Tirta Fresindo Jaya

8. $\quad$ PT. Prima Cahaya Indobaeverage

9. PT. AJE Indonesia

10. PT. Suntory Garuda Beverage

11. PT Heinz ABC Indonesia

12. PT. Berkah Hajat Mandiri

13. PT. Ajinomoto Calpis Beverage Indonesia

14. PT. Monysaga Prima

15. PT. ABC President Indonesia

16. PT. Multi Bintang Indonesia

17. PT. Berri Indosari

No Jenis Minuman

1 Aerated Waters

2 Flavoured UHT Milk Drinks

3 Coffee based drinks or coffee flavoured drinks

$4 \quad$ Mixtures of juices, Ready for immediate consumption
Jumlah Importir

10

2

10

10

Pengecualian subjek dapat diberikan kepada produsen minuman berpemanis dalam negeri yang mengekspor produk ke negara lain dalam jumlah tertentu. Hal ini bertujuan untuk merangsang pertumbuhan ekonomi melalui ekspor.

\section{Objek Pungutan}

Objek pungutan terhadap minuman berpemanis ialah jenis minuman ringan yang pada dasarnya menggunakan gula dan pemanis buatan dimana dalam pembuatannya tersebut melalui proses kimiawi. Objek Pungutan minuman berkarbonasi ialah minuman yang mengandung air karbonasi dan gula berlebih dimana, air inilah yang membuat minuman berkarbonasi berbahaya karena berasal dari gas $\mathrm{CO} 2$ yang terlarut di dalam air sehingga ketika minuman tersebut di buka 
dari tutupnya akan menghasilkan buih akibat dari pelepasan gas $\mathrm{CO}$. Beberapa jenis minuman tersebut dapat diemukan di dalam teh kemasan, minuman rasa buah, minuman ringan bersoda, minuman berenegi, dan minuman olah raga (Sports drink) (Ameribev.org dalam ariani 2012). Berikut ini merupakan Komposisi Minuman Berkarbonasi:

\begin{tabular}{|c|c|}
\hline \multicolumn{1}{|c|}{ Komposisi } & \multicolumn{1}{c|}{ Keterangan } \\
\hline $\begin{array}{c}\text { Air } \\
\text { Berkarbonasi }\end{array}$ & Dibuat dengan cara melewatkan es kering (dry ice) kedalam air es \\
\hline Bahan Pemanis & $\begin{array}{l}\text { 1. Bahan pemanis natural = gula pasir, gula cair, gula invert cair, sirup } \\
\text { jagung dengan kadar glukosa tinggi, dan dekstrosa. } \\
\text { 2. Bahan Pemanis Intetik = Sakarin (Bahan Pemanis yang disarankan Food } \\
\text { \& Drugs Administration Standard, Amerika Serikat) }\end{array}$ \\
\hline Zat Asam & $\begin{array}{l}\text { Asam sitrat, asam fosfat, asam malat, asam fumarat, asam adipat, dll } \\
\text { Akstrak alkoholik, larutan alkoholik, emulsi, fruit juices, kafein, ektrak } \\
\text { biji kola, dan sintetik flavor) }\end{array}$ \\
\hline Zat Pewarna & $\begin{array}{l}\text { 1. Zat pewarna Natural = grape, strawberry, cherry, dll } \\
\text { 2. Zat pewarna semi sintetik = Caramel color. } \\
\text { 3. Zat pewarna sintetik }\end{array}$ \\
\hline Zat Pengawet & Asam sitrat untuk mencegah fermentasi dan sodium benzoate. \\
\hline
\end{tabular}

Berikut ini merupakan komposisi beserta tarif cukai yang berlaku untuk minuman non alkohol di Thailand:

\begin{tabular}{|l|c|c|}
\hline \multicolumn{1}{|c|}{ Jenis Minuman non alkohol } & Tarif Advalorem (\%) & Tarif Spesifikasi \\
\hline $\begin{array}{l}\text { Air mineral buatan, air soda, dan minuman } \\
\text { ringan tanpa gula atau zat pemanis }\end{array}$ & - & 37 Baht/440 c.c \\
\hline $\begin{array}{l}\text { Air mineral dan minuman ringan dengan gula } \\
\text { atau bahan pemanis lainnya atau minuman } \\
\text { ringan lainnya tanpa alkohol termasuk sari } \\
\text { buah atau sari sayur }\end{array}$ & $12 \%$ & \\
\hline $\begin{array}{l}\text { Minuman sari buah dan sayur tanpa fermentasi } \\
\text { termasuk sari buah anggur tanpa tambahan } \\
\text { alkohol atau bahan pemanis tambahan }\end{array}$ & & \\
\hline $\begin{array}{l}\text { Minuman sari buah dan sayur termasuk sari } \\
\text { buah anggur tanpa alkohol dengan atau tanpa } \\
\text { gula atau bahan pemanis lainnya yang } \\
\text { komposisinya telah mendapat izin dari } \\
\text { peraturan pemerintah }\end{array}$ & & \\
\hline
\end{tabular}




\section{Tarif}

Terdapat beberapa konsep Tarif yakni, (1) Tarif Advalorum (Presentase), bea masuk dikenakan dengan menentukan presentase (\%) tertentu dari nilai pabean atas barang yang di impor, (2) Tarif Spesifik, bea masuk dikenakan dengan menentukan besaran bea masuk setiap satu barang yang diimpor, (3) Tarif Gabungan Advalorum, bea masuk dikenakan dengan mengkombinasikan tarif persentase dan tarif spesifik sekaligus pada suatu barang impor. tarif tersebut didasari oleh Undang-undang No 17 Tahun2006 tentang Perubahan Undang-undang No 10 Tahun 1995 tentang kepabean (bppk.kemenkeu 17/11/2014).

Di Meksiko pada 2014, minuman berpemanis dikenakan cukai sebesar 1 Peso per-liter. Sedangakan, di Finlandia pengenaan pada Sugar tax dilakukan sejak tahun 2017 dengan tarif 0,220 euro per-liter untuk minuman yang memiliki $5 \%$ gula, dan 0,11 euro per-liter untuk minuman nonalkohol lainnya. tingginya pengenaan cukai atas minuman berpemanis ini di lakukan negara Perancis yang mengenakan tarif sebesar 7,16 euro per-liter dengan kriterian minuman yang memiliki gula sekitar 6\% dari harga produk (Rosyada \& Ardiansyah). Dari ke 3 negara tersebut dalam pemungutannya menggunakan jenis tarif Spesifik.

Di Indonesia sendiri, Menteri Keuangan Sri Mulyani telah membuat kebijakan cukai atas minuman berpemanis dengan tarif yang di usulkan sebesar Rp 1.500 per-liter untuk minuman teh kemasan dan Rp 2.500 per-liter untuk minuman berkarbonasi. Jika tarif tersebut digunakan maka diprediksi potensi penerimaan negara atas cukai minuman berpemanis bisa mencapai $\mathrm{Rp} 6,25$ triliun (BBC 21/02/2020) yang menandakan keberhasilan penerapan cukai minuman dimana masyarakat baik konsumen akan beralih ke minuman non-berpemanis. Ini sejalan dengan tujuan pnerapan cukai minuman berpemanis, yakni untuk mengubah prilaku konsumsi masyarakat terhadap minuman berpemanis. Dalam penentuan tarif cukai atas minuman berpemanis perlu di tinjau kembali, janganlah terlalu tinggi agar tidak mengganggu perekonomian, namun juga jangan terlalu rendah sehingga tidak dapat mengubah pola konsumsi masyarakat pada minuman berpemanis. Sehingga, Indonesia dapat belajar dari negara-negara yang telah berhasil menerapkan kebijakan tersebut dimana, tarif pengenannya menyesuaikan berdasarkan jumlah pemanis yang digunakan, semakin banyak kandungan pemanisnya maka tarif yang dikenakan akan semakin tinggi. Berikut ini perhitungan besaran tarif cukai jika menggunkan perhitungan hungaria yang.

\begin{tabular}{|c|c|c|c|c|c|c|}
\hline $\begin{array}{c}\text { Jenis } \\
\text { Minuman }\end{array}$ & $\begin{array}{c}\text { Nama } \\
\text { Produk } \\
\text { (Sampel) \& } \\
\text { ukuran }\end{array}$ & $\begin{array}{c}\text { Harga } \\
\text { produk } \\
\text { sebelum } \\
\text { cukai }\end{array}$ & $\begin{array}{c}\text { Tarif cukai } \\
\text { dalam } \\
\text { HUF/Liter }\end{array}$ & $\begin{array}{l}\text { Tarif cukai } \\
\text { dalam } \\
\text { Rp/Liter }\end{array}$ & $\begin{array}{c}\text { Besar } \\
\text { pengenaan } \\
\text { cukai }\end{array}$ & $\begin{array}{c}\text { Harga } \\
\text { produk } \\
\text { setelah Cukai }\end{array}$ \\
\hline Berkarbonasi & $\begin{array}{c}\text { Coca-Cola } \\
390 \mathrm{ml}\end{array}$ & Rp. 4.500 & $250 \mathrm{Huf} / \mathrm{l}$ & Rp12.328/liter & Rp. 4.088 & Rp. 8.588 \\
\hline $\begin{array}{c}\text { Teh } \\
\text { Kemasan }\end{array}$ & $\begin{array}{c}\text { Teh Pucuk } \\
350 \mathrm{ml}\end{array}$ & Rp 3.500 & $250 \mathrm{Huf} / 1$ & Rp12.328/liter & Rp. 4.315 & $\operatorname{Rp} 7.815$ \\
\hline Perisa Buah & $\begin{array}{l}\text { Buavita } \\
250 \mathrm{ml}\end{array}$ & Rp 6.000 & 200 Huf/l & Rp9.863/liter & Rp 2.465 & Rp 8.465 \\
\hline Susu & $\begin{array}{c}\text { Ultramilk } \\
250 \mathrm{ml}\end{array}$ & Rp 6.000 & 7 Huf/l & Rp345,21/liter & Rp. 86,3 & Rp 6.086 \\
\hline Berkafein & $\begin{array}{l}\text { Good day } \\
250 \mathrm{ml}\end{array}$ & Rp 6.000 & 250 Huf/l & Rp12.328/liter & Rp 3.082 & Rp 9.082 \\
\hline
\end{tabular}




\section{Revenue Recycling}

Penerimaan negara yang berasal dari pungutan minuman berpemanis hendaknya digunakan untuk membiayai eksternalitas negatif yang timbul dari minuman berpemanis dan berkarbonasi. Pemanfaatan penerimaan ini dapat berupa:

1. Penelitian dan pengembangan metode pengobatan diabetes

2. Pembiayaan jaminan Kesehatan yang dialokasikan khusus penderita penyakit diabetes

Dalam hal ini, beberapa negara juga menerapkan kebijakan pengalokasian dana atas penerimaan sugar-sweetened beverages tax . Pertama, Hungaria dimana penerimaan atas pajak tersebut digunakan kembali sebagai upaya peningkatan kesehatan berupa pengalihan pasokan makanan ke produk yang lebih sehat (BİrÛ: 2015). Kedua, Zambia penerimaan atas sugarsweetened beverages akan digunakan untuk mempromosikan pola makan dan gaya hidup sehat serta melengkapi dana Jaminan Kesehatan Nasional yang baru di perkenalkan (Hangoma, et al: 2020). Disamping itu, Inggris akan mengalokasikan penerimaan dari sugar-sweetened beverages untuk klub sarapan dan olahraga disekolah (Meyer, et al: 2017).

\section{Dampak Pungutan Minuman Berpemanis dan Berkarbonasi di Indonesia}

\section{Menambah Penerimaan negara}

Dengan pengenaan cukai atas minuman berpemanis dapat menambah penerimaan negara. Dimana, jika penerapannya dengan tarif Rp 1.500 untuk minuman berpemanis dan Rp 2.500 untuk minuman berkarbonasi, maka Potensi dari Penerimaan Cukai tersebut diperkirakan mencapai Rp 6,25 triliun yang dapat menambah penerimaan negara, dan pengenaannya akan dialokasikan untuk program-program peningkatan kesehatan. Sedangkan, dinegara yang berhasil menerapkan pengenaan cukai atas minuman berpemanis sebagai contoh Berkeley, California penerimaan negara atas cukai minuman berkarbonasi sekitar \$2 juta dan pengenaannya digunakan untuk meningkatkan nutrisi dan mengurangi konsumsi dan di negara Meksiko pada tahun 2014 pendapatan dari penerimaan Cukai minuman berpemanis mencapai USD \$1,2 miliar (Roache \& Gostin: 2017).

\section{Penurunan konsumsi minuman berpemanis dan berkarbonasi}

Dengan diterapkannya cukai minuman berpemanis diperkirakan akan menurunkan potensi konsumsinya. Hal ini, didukung oleh WHO yang menyatakan bahwa kenaikan harga minuman berpemanis dapat mempengaruhi penurunkan konsumsi sebanyak 20\% (Kompas 19/02/2020). di meksiko sendiri kebijakan pengenaan cukai atas minuman berpemanis dapat menurunkan konsumsi sebanyak 12\% kapital per-hari (Rosyada \& Ardiansyah; 2018), Sedangkan, di berkeley pengenaan cukainya dapat menurunkan konsumsi sugar sweetened beverages Sebesar $21 \%$, (Roache \& Gostin: 2017). Karena terjadinya penurunan konsumsi tersebut maka akan berdampak pada penurunan penjualan terkait.

Penurunan penjualan ini dapat dilihat pada tahun 2016 produk teh kemasan berproduksi mencapai 2,19 Miliar liter, sedangkana minuman berkarbonasi sebanyak 747 juta liter dan minuman lainnya seperti energy drink, kopi, konsentrat, dan lainnya sebanyak 808 juta liter diperkirakan, jika cukai diterapkan maka perkiraan produksi minuman berpemanis akan turun menjadi 2,02 miliar liter untuk teh kemasan, 687 juta liter untuk minuman berkarbonasi, dan sebanyak 743 juta liter untuk minuman lainnya (Katadata 24/02/2020).

\section{Subtitusi minuman berpemanis dan berkarbonasi}

Kenaikan harga akibat pengenaan cukai atas minuman berpemanis dan berkarbonasi memberikan potensi konsumsinya berpindah keminuman jenis lain. Indonesia dapat berkaca dari negara-negara yang telah berhasil menerapkan Cukai atas minuman berpemanis dimana, dengan adanya tarif tersebut membuat potensi konsumen berpindah ke minuman jenis lain seperti di meksiko yang menyebabkan terjadinya peningkatan pembelian minumam non-gula yakni air mineral sebanyak 2,1\% hal ini didasari penelitian dari Mexican National Institute of Public Health and University of North Carolina pada tahun 2014-2015. Sedangkan di Berekley California pengenaan tarifnya membuata penjualan air kemasan meningkat sebesar 15,6\% (Chalaoupka, et al; 2019). 


\section{Pemutusan hubungan kerja}

Akibat penurunan produksi dapat menurunkan pendapatan yang pasti akan berdampak pada pengurangan jumlah tenaga kerja guna menekan biaya produksi. Hal ini terjadi pada negara Arab Saudi yang telah menerapkan cukai minuman berpemanis dimana, kenaikan pengenaan cukai menyebabkan harga jualnya naik mencapai 55\% yang terdiri dari 50\% cukai dan 5\% PPN yang berdampak terhadap penurunan penjualan sehingga, hal tersebut berakibat terhadap harga minuman yang mengakibatkan terjadinya pengurangan karyawan (Alsukait, et al:2020).

\section{Penurunan penerimaan beberapa jenis pajak}

Apa bila cukai minuman berpemanis di terapkan di Indonesia maka diperkirakan akan terjadi penurunan penerimaan negara sebesar 700 Miliar (bcc 21/02/2020). Hal ini merupaka dampak dari meningkatnya harga minuman berpemanis, sehingga tingkatan konsumsi masyarakat akan menurun yang berpengaruh pada jumlah laba pengusaha minuman berpemanis. Dengan berkurangnya laba perusahaan, dapat berujung pada Pemutusan Hubungan Kerja (PHK), maka penerimaan negara dari pph badan dan pph 21 akan menurun. Pengurangan laba perusahaan akan mengurangi penerimaan pemerintah dan membebani perekonomian secara makro. Selain penurunan penerimaan Pajak pengenaan cukai atas minuman berpemanis juga mengarahkan ke tindakan penghindaran dan penggelapan pajak, dimana hal ini merupakan pengalaman dari seluruh dunia yang memberika argumen (Chalaoupka, et al; 2019).

\section{KESIMPULAN}

Hasil penelitian menunjukkan bahwasanya aspek pungutan minuman berpemanis dapat diterapkan pada level produsen dan importir namun dengan pengecualian tertentu. Tarif yang dikenakan juga hendaknya disesuaikan tiap tahunnya agar pengenaan cukai minuman berpemanis tidak sekadar untuk mengeruk penerimaan namun juga berdampak pada penurunan konsumsi minuman berpemanis.

Secara umum, di beberapa negara mampu menurunkan tingkat konsumsi minuman berpemanis yang berujung pada penurunan penderita diabetes. Namun atas pungutan ini, berdampak negatif secara makro ekonomi seperti penurunan daya beli yang berujung pada pemutusan hubungan kerja di sektor inustri minuman berpemanis. Selain itu juga berdampak pada penurunan jenis pajak lainnya.

\section{DAFTAR PUSTAKA}

Akhriani, M., Fadhilah, E., \& Kurniasari, F. N. (2016). Hubungan Konsumsi Minuman Berpemanis Dengan Kejadian Kegemukan Pada Remaja di SMP Negeri 1 Bandung . Indonesian Journal of Human Nutrition, 29.

Alsukait, R., Bleich, S., Wilde, P., Singh, G., \& Folta, S. (2020). Sugar Drink Excise Tax Policy Process and Implementation: Case Study From Saudi Arabia. Food Policy.

Ariani, S. (2012). Hubungan Antara Faktor Individu dan Lingkungan Dengan Konsumsi Minuman Ringan Berpemanis Pada Siswa/I SMA Negeri 1 Bekasi Tahun 2012. Skripsi .

Asosiasi Industri Minuman Ringan \& Food Review. (2012, 04 28). Prospek dan Tren Industri Minuman Ringan Indonesia Memasuki $2012 . \quad$ Indonesia: https://kemenperin.go.id/jawaban_attachment.php?id=6023\&id_t=21964.

Badan Penelitian dan Pengembangan Kesehatan . (2018, 11 07). Hasil Utama RISKESDAS 2018. Indonesia: kemenkes.go.id.

BÌrÛ, A. (2015). Did the junk food tax make the Hungarians eat. Edinburgh Research Explorer .

Blecher, E., Liber, A. C., Drope, J. M., Nguyen, B., \& Stoklosa, M. (2017). Peer Reviewed:: Global Trends In The Affordability of Sugar-Sweetened Beverages, 1990-2016. Priventing Chronic Didease .

Buckton, C. H., Fregie, G., Leifeld, P., \& Hilton, S. (2019). A Discourse Network Alanysis of UK Newspaper Coverage of The "Sugar Tax" Debate Before and After The Announcement of The Soft Drinks Industry Levy. BMC Public Health . 
Chandra, E. M. (2008). Kajian Ekstensifikasi Barang Kena Cukai Pada Minuman Ringan Berkarbonasi. Skripsi .

Direktorat Pengendalian Penyakit Tidak Menular, Direktorat Jenderal Pengendalian Penyakit dan Penyehatan Lingkungan, dan Departemenn Kesehatan Republik Indonesia. (2008). Pedoman Pengendalian Diabetes Melitus dan Penyakit Metabolik. Jakarta: Menteri Kesehatan Republik Indonesia.

Falbe, J., Rojas, N., Grummon, A. H., \& Madsen, K. A. (2015). Higher Retail Prices of Sugar-Sweetened Beverages 3 Months After Implementation of an Excise Tax in Berkeley, California. American Journal of Public Health .

James, E., Lajous, M., \& Reich, M. R. (2020). The Politics of Taxes for Health: An Analysis of the Passage of the Sugar-Sweetened Beverage Tax in Mexico. Health Systems \& Reform .

Khairani. (2018). Hari Diabetes Sedunia Tahun 2018. InfoDATIn (Pusat Data dan Informasi Kementerian Kesehatan RI) , 3.

Manurung, R. D., \& Panjaitan, C. V. (2019). Gambaran karakteristik penderita diabetes melitus yang berobat jalan ke poli interna RSUP H.Adam Malik Medan. Politeknik Kesehatan Kemenkes Medan Jurusan Keperawatan , 2.

Roache, S. A., \& Gostin, L. O. (2017). The Untapped Power of Soda Taxes: Incentivizing Consumers, Generating Revenue, and Altering Corporate Behavior. International Journal of Health Policy and Management .

Rosyada, H., \& Ardiansyah, B. G. (2018). Analisis fisibilitas pengenaan cukai atas minuman berpemanis (sugar-sweetened beverages) . Kajian Ekonomi \& Keuangan, 234.

Subdirektorat Statistik Impor. (2019). DIREKTORI IMPORTIR INDONESIA 2018. JAKARTA: Badan Pusat Statistik, Jakarta-Indonesia.

Swerdloff, A. (2018, 01 16). Penelitian: Begini Alasan Manusia Suka Banget Air Bersoda. Indonesia : Vice.com.

Tansuria, B. I. (2012). Sistem Pemungutan Pajak di Indonesia dan Pajak Penghasilan Yang Bersifat Final. Journal of Business and Economics .

\section{Sumber Lain}

Alika, R. (2020, 02 24). Tolak Cukai Minuman Manis, Asosiasi: Pendapatan Usaha Kecil Bisa Turun. Jakarta, DKI Jakarta, Indonesia: Katadata.co.id.

Asosiasi Industri Minuman Ringan. (t.thn.). Daftar Anggota. Dipetik 09 30, 2020, dari asrimindonesia.org: http://asrim-indonesia.org/anggota/

Jafar, M. (2014, 11 17). Kajian Atas Pengenaan Bea Masuk Menggunakan Tarif Spesifik. Dipetik 10 4, 2020, dari bppk.kemenkeu.go.id: https://bppk.kemenkeu.go.id/content/berita/pusdiklat-beadan-cukai-kajian-atas-pengenaan-bea-masuk-menggunakan-tarif-spesifik-2019-11-05$4 \mathrm{e} 2 \mathrm{~d} 8937 /$

Maharrani, A. (2019, 07 02). BPJS kesehatan keluarkan Rp6,1 triliun untuk tangani diabetes. Jakarta, DKI Jakarta, Indonesia: Beritagar.id.

Nursastri, S. A. (2020, 02 9). Sri Mulyani Ingin Minuman Berpemanis Dikenakan Cukai, Ini Kata WHO. Jakarta, DKI Jakarta, Indonesia: Kompas.com.

Swerdloff, A. (2018, 01 16). Penelitian: Begini Alasan Manusia Suka Banget Air Bersoda. Indonesia : Vice.com.

Tim BBC News Indonesia. (2020, 02 21). Minuman Berpemanis diusulkan kena cukai: Ditolak pengusaha tapi di dukung dokter. jakarta, DKI Jakarta, Indonesia: bbc.com. 
Tim Nielsen. (2018, 05 09). RIUH RENDAH KOMPETISI PELEPAS DAHAGA. Dipetik 09 26, 2020, dari nielsen.com: https://www.nielsen.com/id/en/insights/article/2018/riuh-rendah-kompetisipelepas-dahaga/

Tim. CNN Indonesia. (2020, 02 20). Bahaya Minuman Berkarbonasi dan Berpemanis. Jakarta, DKI Jakarta , Indonesia: cnnindonesia.com. 